\title{
Prevention of Frey Syndrome
}

\author{
Tapati Biswas ${ }^{1}$, Rangaswamy Shruthi ${ }^{2}$, Madhumati Singh ${ }^{3}$
}

\begin{abstract}
Aim and objective: This article reviews various methods for prevention of Frey syndrome.

Background: Frey syndrome is a late postoperative phenomenon seen mostly after parotidectomy procedures, trauma to the parotid gland, facelift procedures, and rarely after neck dissections. First discovered by Baillarger in 1853 and later described by Lucja Frey in 1923, it is characterized by gustatory sweating and flushing. It results from damage to the sympathetic and parasympathetic nerve supply to the face and the parotid gland. The patients suffering from this syndrome initially complain of sweating near the ear, face, and forehead site on mastication. Clinical significance: Frey syndrome is a condition associated with psychological concerns among patients and exhibits as a social embarrassment. The need for prevention of this syndrome is thereby necessary to provide patients with improved quality of life. Various medical as well as surgical methods have been employed to prevent Frey syndrome.

Conclusion: This review article encompasses these various medical and surgical procedures. Long term studies are still to be done to evaluate the efficacy of the surgical procedures.

Keywords: Extended polytetrafluoroethylene, Frey syndrome, Gustatory sweating, Lyophilized dura, Platysma muscle flap, Polyglactin, Sternocleidomastoid flap, Superficial musculo-aponeurotic flap, Temporoparietal fascial flaps.

Journal of Health Sciences \& Research (2020): 10.5005/jp-journals-10042-1086
\end{abstract}

\section{INTRODUCTION}

Frey syndrome is a late postoperative complication found mostly after parotid gland surgeries, face lift procedure, trauma, and to less extent with neck dissection. ${ }^{1}$ It is a neurological disorder that was first discovered by Baillarger in 1853 and was later described by Lucja Frey in the year $1923 .^{2}$ The pathophysiology of Frey syndrome was first given by the French pediatric neurologist AndreThomas. ${ }^{3}$ Frey's syndrome is also known as Baillarger syndrome, Dupuy's syndrome, Auriculotemporal syndrome, and Gustatory hyperhydrosis. The rate of occurrence of Frey syndrome is found to be $3-50 \%$ following parotid gland surgeries. It is generally seen at a minimum of 2 months after surgery with late occurrence extending up to 5 years with a mean of 22.2 months. ${ }^{4}$

\section{Pathophysiology}

The widely accepted theory for Frey's syndrome is that it results due to damage to both sympathetic and parasympathetic nerves supplying the face and parotid gland. The parasympathetic nerves are a part of autonomic nervous system supplying the parotid gland. Sympathetic nerve on the other hand supplies the sweat glands and blood vessels. ${ }^{1}$

During any nerve injury, the damaged fibers start regenerating. In Frey syndrome, these parasympathetic fibers regenerate along the fibers of sympathetic pathway and thereby supply the sweat gland. These parasympathetic fibers normally supply parotid gland which produces saliva while eating, but due to their aberrant regeneration along the sympathetic nerve fiber pathway, there is sweating of face while mastication leading to excessive sweating on eating certain kind of foods. ${ }^{1}$

\section{Signs And Symptoms}

The signs and symptoms tend to appear within a year or after a year of parotidectomy or any blunt trauma. Sometimes, the symptoms
1,3 Department of Oral and Maxillofacial Surgery, RajaRajeswari Dental College and Hospital, Bengaluru, Karnataka, India

${ }^{2}$ Rajiv Gandhi University of Health Science, Bengaluru, Karnataka, India Corresponding Author: Tapati Biswas, Department of Oral and Maxillofacial Surgery, RajaRajeswari Dental College and Hospital, Bengaluru, Karnataka, India, Phone: +91 7829397309, email: tapatibiswas90@gmail.com

How to cite this article: Biswas T, Shruthi R, Singh M. Prevention of Frey Syndrome. J Health Sci Res 2020;11(1):17-20.

Source of support: Nil

Conflict of interest: None

might take years to manifest. The patients suffering from this syndrome initially complain of sweating near the ear, face, and forehead site while eating certain kinds of food such as sour, salty, or spicy. Other symptoms of Frey syndrome are flushing, burning, itching, and neuralgia. The area affected and intensity by Frey syndrome differs from patient to patient.

\section{DiAgNOSIS}

Diagnosis of Frey syndrome is not only based on clinical symptoms but also done by Minor's starch iodine test. This test was first described by Victor Minor in 1928. It is a qualitative test to evaluate pseudo-motor function.

The test is done by applying tincture of iodine over the skin of the affected site and allowed to dry following which the area is dusted with corn starch or potato flour. Sweating is induced at room temperature by asking the patient to suck on a lemon candy for 10 minutes. Due to sweating over the skin, the starch iodine complex changes color from yellow to blue or brown which is indicative of Frey syndrome.

(-) The Author(s). 2020 Open Access This article is distributed under the terms of the Creative Commons Attribution 4.0 International License (https://creativecommons. org/licenses/by-nc/4.0/), which permits unrestricted use, distribution, and non-commercial reproduction in any medium, provided you give appropriate credit to the original author(s) and the source, provide a link to the Creative Commons license, and indicate if changes were made. The Creative Commons Public Domain Dedication waiver (http://creativecommons.org/publicdomain/zero/1.0/) applies to the data made available in this article, unless otherwise stated. 


\section{Surgical Methods of Preventing Frey SYNDROME}

The main objective of surgical treatment is to create a barrier between the underlying post ganglionic parasympathetic nerve fibers within the transected parotid gland and the overlying tissue. Use of increased skin flap thickness, local fascia or muscle flap, acellular dermal matrix, irradiated animal pericardial membrane, implants, and fat grafts has been advocated for surgical management.

\section{Increased Thickness of Skin Flap}

Increased thickness of skin flaps reduces exposure of sweat glands and thereby prevents the aberration of the post ganglionic parasympathetic fibers responsible for Frey syndrome. Although recent studies were inconclusive about the reduction in incidence of Frey syndrome with increased thickness of skin flap, but it effectively reduces the skin surface area affected by the syndrome. ${ }^{2,3,5}$

\section{Transposition of Muscle or Fascia Flaps}

Pedicled muscle or fascia flaps have been used as a barrier between transected nerve fibers of the parotid gland and the overlying skin.

\section{Temporoparietal Fascia Flap}

It is a well-vascularized flap based on superficial temporal artery with a broader surface area. This flap was initially used in the reconstruction of cheek, ear, nasal cavity, and orbit but has been used by Sultan et al. in 1995 to prevent incidence of Frey syndrome following parotid gland surgeries. The result of this study showed prophylactic prevention of Frey syndrome in all the seven patients both clinically and by starch iodine testing. Multiple studies have been done to substantiate the use of this flap for prevention of Frey syndrome. These studies showed a decrease of incidence of Frey syndrome by starch iodine testing from 4 to $17 \%$ and reduced clinical incidence of gustatory sweating from 4 to $8 \%$.

Although this flap has proved to be useful in prevention of the syndrome, this requires a second incision and poses potential risk due to presence of superficial temporal artery. This also increases the operating time and may require a second reconstruction surgery team which thereby increases the cost of the treatment. ${ }^{6,7}$

\section{Sternocleidomastoid Flap}

This muscular flap is mostly favored for reconstruction because of its close proximity to the parotid region and thereby masks the defect created after parotid surgery. This flap derives its blood supply from three arteries-the upper third supplied by the occipital artery, middle third by the superior thyroid artery, and the lower third by the transverse cervical artery. Although this flap is easy to harvest, the use of it to prevent Frey syndrome is not clear. A retrospective study done by Filho et al. on 24 patients following parotid surgery demonstrated that the use of this flap showed no cases of Frey syndrome as assessed by starch iodine test and by the clinical symptoms. Also, a meta-analysis done by Curry et al. in 2009 shows decreased incidence of Frey syndrome. However, due to limited number of studies done and due to heterogenicity of samples, the usage of this flap for prevention of Frey syndrome is still not clear. ${ }^{8-11}$

\section{Interposition of Temporalis and Sternocleidomastoid Flap}

A study done by Dia et al. reviewed 17 patients who underwent corrective procedures with simultaneous TFF and SCMF interposition for the treatment of Frey syndrome. The average area of gustatorysweating positive skin was reduced from 12.80 to $1.32 \mathrm{~cm}^{2}$ postoperatively. The facial asymmetry secondary to parotidectomy was greatly improved. The authors concluded that this technique was efficacious in ameliorating Frey syndrome and facial concavity secondary to parotidectomy. Although use of this interpositional flap is highly compelling, the risks of injuring facial nerve is very high (TFF-temporofascia flap, SCMF- sternocleidomastoid flap). ${ }^{12}$

\section{Superficial Musculoaponeurotic Flap}

Superficial musculoaponeurotic flap is another technique used as barrier between the overlying dermis and the transected parotid gland. This flap can be raised by a preauricular incision, modified Blair or facelift incision, and easily separated from the skin and parotid tissue to be tightly plicated to the sternocleidomastoid muscle, thereby masking the defect. In a study done on 160 patients by Bonanno et al. over a mean period of 8.9 years, there were no patients with clinical symptoms of gustatory sweating, and they were found negative for starch iodine test as well. Few other studies done on the use of this flap did not show any significant difference, although the intensity and the surface area affected due to gustatory sweating was markedly reduced. ${ }^{13-17}$

\section{Platysma Muscle Flap}

This flap has also been used as a barrier between the overlying cutaneous tissue and the transected parotid gland. This flap is rather easy to harvest and can be used to cover the defect. In a study done by Hayashi in 2016 on seven patients, it showed no incidence of Frey syndrome. This can be effectively used in reconstruction of the defect as well as prevent Frey syndrome. However, complete coverage of the defect should be done to prevent any complication. ${ }^{18}$

\section{Biomaterial and Autologous Implantation}

Biomaterials such as acellular dermal matrix have been used as a barrier between the overlying skin and the transected parotid gland. This acellular dermal matrix is a soft tissue matrix made from decellularizing a tissue, making it an intact extracellular graft and acts as a scaffold for regeneration of tissues in wound healing and in reconstruction. Limited number of studies gives us limited data about its effectiveness in reducing both the objective and the clinical manifestation of Frey syndrome. ${ }^{19-21}$

\section{Irradiated Animal Pericardial Membrane}

Collagen membrane derived from animal pericardium is used as a barrier to prevent Frey syndrome. A study done on 40 patients by Gennaro et al. in 2013 concluded that subjective Frey syndrome was seen in $5 \%$ of patients and with no cases reported after starch iodine testing. Complication associated with this was formation of surgical site seroma. Not much of studies has been done to substantiate the use of this material in prevention of Frey syndrome. ${ }^{22}$

\section{Autologous Fat Implant}

Abdominal fat implantation can be used as a barrier to prevent Frey syndrome. However, limited studies and data are not enough 
to substantiate the use of this graft in prevention of the objective as well as clinical measures of Frey syndrome. Harvesting of this graft requires a second incision on the stomach which can lead to surgical site hematoma and seroma formation.

Implants like Ethisorb (polyglactin 910-polydioxanone), e-PTFE (extended polytetrafluoroethylene), and lyophilized dura have been used as a barrier material. In a study conducted by Dulguerov et al. in 1999, use of barrier implant showed incidence of 3\% for subjective and $10 \%$ for objective evaluation. Complications are formation seroma and salivary fistula.

\section{Medical Management of Frey Syndrome}

It is used as an adjunct to the surgical management of prevention of Frey syndrome. These drugs can be administered either via injection or as topical application. Currently, the most commonly used is botulinum toxin A intradermal injection, and the other antiperspirants that were used are alcohol, glycopyrrolate, scopolamine. Use of botulinum toxin A has shown to have improved the quality of life. Although use of this toxin has shown symptomatic recurrence, repeated administration has been found useful. ${ }^{21,23-26}$

\section{Discussion}

Frey syndrome is a complication seen generally after parotidectomy, facelift procedures, and trauma. It occurs due to damage to the parasympathetic and sympathetic nerves supplying the face and parotid gland, where during any nerve injury the damaged fibers start regenerating. Parasympathetic fibers supplying parotid glands regenerate along the fibers of sympathetic nerve supplying the sweat glands leading to the aberration thereby bringing about the clinical manifestation of flushing and sweating around the preauricular area of the injured site during food intake. The symptoms appear to present within or after a year following surgery or trauma.

Diagnosis is based on clinical manifestation and starch iodine test. Various surgical and medical methods have been practiced to prevent the occurrence of Frey syndrome.

Surgical method is based on creating a barrier between the underlying post ganglionic parasympathetic nerves fibers within the transected parotid gland and the overlying tissue. This is achieved by increasing the thickness of the skin flap ${ }^{2,3,5}$ using local fascial and muscle flap like temporoparietal fascial flaps, ${ }^{6,7}$ sternocleidomastoid flap, ${ }^{8-11}$ interpostition of both temporalis and sternocleidomastoid flap, ${ }^{12}$ superficialmusculoaponeurotic flap, ${ }^{13-17}$ platysma muscle flap. ${ }^{18}$

Biomaterials like acellular dermal matrix, irradiated animal pericardial membrane, ${ }^{22}$ and autologous fat have been used as one of the barrier materials. Implants like polyglactin, e-PTFE (extended polytetrafluoroethylene), and lyophilized dura have also been used for the same.

In addition to the surgical methods, medical management of Frey syndrome includes Botulinum toxin A injections or as topical applications. ${ }^{21,23-26}$ Antiperspirants like alcohol, scopolamine, and glycopyrollate is found to be useful.

\section{SUMMARY}

Due to the limited amount of studies, there are a very limited data on the effectiveness of the above-mentioned surgical procedures. These flaps pose a low risk and can be routinely used in the reconstruction of the defect following a total or a superficial parotidectomy.

Acellular dermal matrix is a suitable alternative to the use of local fascia and muscle flaps in prevention of Frey syndrome.

However, if the tumors are found to be neoplastic in nature, use of these flaps are not advised, as there are chances of spillage of tumor which will lead to recurrence.

Symptomatic complaints of Frey syndrome can be given by relieved by use of botulinum toxin $A$ injection. Although it is not a definitive treatment, it does reduce the intensity of gustatory sweating.

\section{Conclusion}

In view of prevention and management of Frey syndrome, although various surgical and medical management have been put forward, there are very limited data on effectiveness of these procedures due to the limited amount of studies conducted.

Due to lack of evidence, symptomatic relief has been the mainstay of treatment of in management of Frey syndrome.

\section{Clinical Significance}

Frey syndrome is a condition associated with psychological concern among patients, as it is considered to be a social embarrassment. Patients suffer from sweating and flushing over the cheek, ear, and forehead region on the affected side while eating. The need for surgical and medical management of Frey syndrome is thereby necessary to improve the quality of life in such patients.

\section{References}

1. Motz KM, Kim YJ. Auriculotemporal syndrome (Frey syndrome). Otolaryngol Clin North Am 2016;49(2):501-509. DOI: 10.1016/j. otc.2015.10.010.

2. Singleton G, Cassisi N. Frey's syndrome: incidence related to skin flap thickness in parotidectomy. Laryngoscope 1980;90:1636-1640.

3. Taylor SM, Yoo J, Matthews TW, et al. Frey's syndrome and parotidectomy flaps: a retrospective cohort study. Otolaryngol Head Neck Surg 2000;122(2):201-203. DOI: 10.1016/S0194-5998(00)70239-7.

4. Langdon JD. Complications of parotidgland surgery. J Maxillofac Surg 1984;12:225-229. DOI: 10.1016/S0301-0503(84)80249-0.

5. Durgut O, Basut O, Demir UL, et al. Association between skin flap thickness and Frey's syndrome in parotid surgery. Head Neck 2012;35(12):1781-1786. DOI: 10.1002/hed.23233.

6. Sultan M, Wider T, Hugo N. Frey's syndrome: prevention with the temporopartietal fascial flap interposition. Ann Plast Surg 1995;34(3):292-297. DOI: 10.1097/00000637-199503000-00012.

7. Ahmen $\mathrm{O}$, Kolhe P. Prevention of Frey's syndrome and volume deficit after parotidectomy using the superficial temporal artery fascial flap. Br J Plast Surg 1999;52(4):256-260. DOI: 10.1054/bjps.1998.0137.

8. Filho WQ, Dedivitis A, Rapoport A, et al. Sternocleidomastoid muscle flap preventing frey syndrome following parotidectomy. World J Surg 2004;28(4):361-364. DOI: 10.1007/s00268-003-7304-1.

9. Curry JM, King N, Reiter D, et al. Meta-analysis of surgical techniques for preventing parotidectomy sequelae. Arch Facial Plast Surg 2009;11(5):327-331. DOI: 10.1001/archfacial.2009.62.

10. Kornblut A. Sternocleidomastoid muscle transfer in the prevention of Frey's syndrome. Laryngoscope 1991;101(5):571-572. DOI: 10.1288/00005537-199105000-00023.

11. Sanabria A, Kowalski LP, Bradley PJ, et al. Sternocleidomastoid muscle flap in preventing Frey's syndrome after parotidectomy: a systematic review. Head Neck 2012;34(4):589-598. DOI: 10.1002/hed.21722. 
12. Dia X, Liu H, He J, et al. Treatment of postparotidectomy Frey syndrome with the interposition of temporalis fascia and sternocleidomastoid flaps. Oral Surg Oral Med Oral Pathol Oral Radiol 2015;119(5):514-521.

13. Bonanno PC, Palaia D, Rosenberg M, et al. Prophylaxis against Frey's syndrome in parotid surgery. Ann Plast Surg 2000;44(5):498-550. DOI: 10.1097/00000637-200044050-00006.

14. Wille-Bischofberger A, Rajan GP, Linder TE, et al. Impact of the SMAS on Frey's syndrome after parotid surgery: a prospective, long-term study. Plast Reconstr Surg 2007;120(6):1519-1523. DOI: 10.1097/01. prs.0000282036.04717.1d.

15. Yu L, Hamilton R. Frey's syndrome: prevention with conservative parotidectomy and superficial musculoaponeurotic system preservation. Ann Plast Surg 1992;29(3):217-222. DOI: 10.1097/00000637-199209000-00005.

16. Allison G, Rappaport I. Prevention of Frey's syndrome with superficial musculoaponeurotic system interposition. Am J Surg 1993;166(4):407-410. DOI: 10.1016/S0002-9610(05)80343-5.

17. Barberá R, Castillo F, D'Oleo C, et al. Superficial musculoaponeurotic system flap in partial parotidectomy and clinical and subclinical Frey's syndrome. Cosmesis and quality of life. Head Neck 2014;36(1):130-136. DOI: 10.1002/hed.23215.

18. Hayashi A, Mochizuki M, Suda S, et al. Effectiveness of platysma muscle flap in preventing Frey syndrome and depressive deformities after parotidectomy. J Plast Reconstr Aesthet Surg 2016;69(5): 663-672. DOI: 10.1016/j.bjps.2015.12.021.

19. Govindaraj S, Cohen M, Genden EM, et al. The use of acellular dermis in the prevention of Frey's syndrome. Laryngoscope 2001;111(11): 1993-1998. DOI: 10.1097/00005537-200111000-00024.
20. Ye WM, Zhu HG, Zheng JW, et al. Use of allogenic acellular dermal matrix in prevention of Frey's syndrome after parotidectomy. Br J Oral Maxillofac Surg 2008;46(8):649-652. DOI: 10.1016/j. bjoms.2007.11.006.

21. Wang W, Fan J, Sun CJ, et al. Systemic evaluation on the use of acellular matrix graft in prevention of Frey syndrome after parotid neoplasm surgery. J Craniofac Surg 2013;24(5):1526-1529. DOI: 10.1097/SCS.0b013e31828dcdb3.

22. Gennaro P, Di Curzio P, Mitro V, et al. Use of irradiate animal pericardiummembrane for prevention of Frey's syndrome after parotidectomy. Eur Rev Med Pharmacol Sci 013;17(4): 548-551.

23. Beerens $A$, Snow $G$. Botulinum toxin $A$ in the treatment of patients with Frey syndrome. Br J Surg 2002;89(1):116-119. DOI: 10.1046/j.00071323.2001.01982.x.

24. Tugnoli V, Marchese Ragona R, Eleopra R, et al. The role of gustatory flushing in Frey's syndrome and its treatment with botulinum toxin type A. Clin Auton Res 2002;12(3):174-178. DOI: 10.1007/s10286-0020026-x.

25. Laccourreye O, AkI E, Gutierrez-Fonseca R, et al. Recurrent gustatory sweating (Frey's syndrome) after intracutaneous injection of Botulinum toxin type A: incidence, management, and outcome. Arch Otolaryngol Head Neck Surg 1999;125(3):283-286. DOI: 10.1001/ archotol.125.3.283.

26. Li C, Wu F, Zhang Q, et al. Interventions for the treatment of Frey's syndrome. Co-chrane Database Syst Rev 2015(3):CD009959. DOI: 10.1002/14651858.CD009959.pub2. 